\title{
Evaluation of the application of cool materials in urban spaces: A case study in the center of Florina
}

\author{
Stamatis Zoras*, Antonios Tsermentselis, Panagiotis Kosmopoulos, Argiro Dimoudi \\ Laboratory of Environmental and Energy Efficient Design of Buildings and Settlements, Department of Environmental Engineering, Democritus University of \\ Thrace, Vas. Sofias 12, Greece
}

\section{A R T I C L E I N F O}

\section{Keywords:}

Cool materials

CFD modeling

Open space

\begin{abstract}
A B S T R A C T
In the last years there is a strong interest for application of bioclimatic techniques and practices in urban neighborhoods and open spaces. This paper presents a bioclimatic study of an open space in an urban area by the use of simulation tools giving emphasis on the replacement of conventional materials with cool materials. Routes linking traditional monuments in the Greek city of Florina are characterized of decreased human thermal comfort conditions during summer time. The employment of computational fluid dynamics has contributed in the understanding of what interventions should be made on urban populated routes in order to meet defined thermal related targets during the warmest day of the year. The proposed replacement of conventional materials by "cool" ones would result in the reduction of the mean surface temperature by $3.52{ }^{\circ} \mathrm{C}$ while the mean maximum air temperature would be reduced by $1.39^{\circ} \mathrm{C}$ during noon of the warmest day.
\end{abstract}

(c) 2014 Elsevier B.V. All rights reserved.

\section{Introduction}

It is widely approved that densely urban developments in conjunction with the use of inappropriate external materials, the increased thermal energy emission related to human related and the lack of green areas, increase environmental temperature, leading to significant environmental impacts and increased energy consumption (Fintikakis et al., 2011). Open spaces within urban developments are complicated due to thermal energy exchange between structures, shadowing and wind flow complication in comparison to general flow. Cool material and other practices (water surfaces, green roofs) are used to mitigate urban heat island effect (Gartland, 2008). The main problems that result from bad thermal conditions in settlements include decreased human thermal comfort, decreased air quality, increased heat illnesses and increased energy and water use.

Experimental measurements within urban developments are needed in order to identify the thermal situation. In the Greek territory there are intense thermal phenomena mainly during the summer period (Dimoudi, Kantzioura, Zoras, Pallas, \& Kosmopoulos, 2013; Livada, Santamouris, Niachou, Papanikolaou, \& Mihalakakou, 2002). These are observed in open urban areas

\footnotetext{
* Corresponding author. Tel.: +30 6944840073; fax: +30 2541079744.

E-mail addresses: stamatis.zoras@gmail.com, szoras@env.duth.gr (S.Zoras).
}

all around country. Surface temperatures in relation to microclimatic conditions (wind, temperature, radiation) must be analyzed in order to better select rehabilitating strategy of open developments.

Simulation tools must be employed (Stavrakakis et al., 2011) in order to depict the present situation around the opencast area, usually during the warmest day of the hot period. Materials identification and constructions configuration must also be taken into account in the simulation process. New materials and bioclimatic techniques are then proposed and simulated in order to show their impact at the thermal urban environment. The aim of this procedure is to realize the microclimatic conditions improvement due to the rehabilitating bioclimatic techniques and practices. The selection of the appropriate measures depends on the targets that will be defined for achieving an improved thermal environment (e.g. thermal comfort).

Due to the complicated urban environment in terms of materials, reflection, emission, wind flows around buildings, altitude differences etc., the simulation tool must be selected very carefully. It must be able to simulate three dimensional flows with solar radiation taken into account. This inevitably leads to general codes of computational fluid dynamics tools (e.g. PHOENICS software tool) but with increased demand of computational resources. Other tools may be useful for the assessment of individual parameters, as surface materials and trees may influence thermal comfort (Matzarakis, Rutz, Mayer, 2006) but they would not assess the wind flow effect in geometrical detail. 
This paper presents a bioclimatic study of an open urban complex space in a city of North Western Greece, Florina, giving emphasis on the replacement of conventional materials with cool materials. The has been carried out in the framework of MSc thesis. The studied area includes the routes linking traditional neighborhoods by the river side of the city. Experimental measurements, simulation tool verification and the simulation based assessment of the proposed redevelopment measures are presented. All simulations have been carried out by the ANSYS CFD software package.

The thermal targets of this study were defined in accordance with the 'Programme for Bioclimatic Redevelopment of Public Open Spaces - Study Guideline' (http://www.cres.gr/kape/ Scientific_Guide_19_7.pdf). These concerned the following parameters that should be improved:

1. Mean maximum summer temperature during noon of the warmest day

2. Mean surface temperature during noon of the warmest day

3. Wind field during the typical summer day

\section{Bioclimatic thermal problem}

Urban climate, compared to the surrounding suburban and rural environment, varies in terms of solar radiation, characteristics of rainfall and air temperature. According to Oke (1973), almost every urban center in the world is warmer $1-4{ }^{\circ} \mathrm{C}$ than neighboring nonurban rural areas, and this enforces urban heat island effects. Also, Gilbert (1991) states that the air temperature on sunny days can be from 2.0 to $6.0^{\circ} \mathrm{C}$ higher in urban compared to suburban locations.

To examine the weather conditions in the city of Florina meteorological data of the period of 1st of January 2009 to the 31st of December 2010 were used from the meteorological stations of Florina that is located in the urban complex of the city. Hourly data were available and the meteorological parameter that was
Table 1

Monthly mean temperatures $\left({ }^{\circ} \mathrm{C}\right)$.

\begin{tabular}{rllllllllllll}
\hline \multirow{2}{*}{ Year } & \multicolumn{1}{l}{ Month } \\
\cline { 2 - 12 } & Jan & Feb & Mar & Apr & May & Jun & Jul & Aug & Sept & Oct & Nov & Dec \\
\hline 2009 & 1.9 & 2.6 & 6.2 & 12.0 & 17.2 & 20.0 & 23.3 & 22.2 & 18.1 & 12.6 & 8.6 & 7.3 \\
2010 & 2.9 & 4.5 & 7.6 & 12.2 & 16.9 & 20.0 & 22.3 & 24.3 & 18.0 & 11.0 & 11.7 & 4.2 \\
\hline
\end{tabular}

examined was the air temperature $\left({ }^{\circ} \mathrm{C}\right)$. From Table 1 , it was concluded that August of 2010 was the hottest month of the two year period.

\section{Bioclimatic interventions}

The open urban complex that was studied belongs to the commercial and social center of Florina city, and it is heavy populated during the week. The urban summer time microclimate in this area is mainly affected by the presence of conventional surface tiles and asphalt all over the linking routes. The ground surface of the river side routes of Florina is covered by Greek (flagstone) (Fig. 1).

The rehabilitation strategy of the area targets to conserve human activities and improve human thermal conditions in the open urban complex. Bioclimatic interventions could be divided into two main directions:

- the river side streets

- the linking streets of the river

The main bioclimatic interventions are characterized by increasing vegetation, green roofs and by installing cool asphalt and flagstones.

In order to improve thermal microclimate in the area new cool materials must be used that may reduce surface temperatures of buildings, streets and sidewalks. The proposed materials have relatively high reflectivity of solar radiation and increased emission
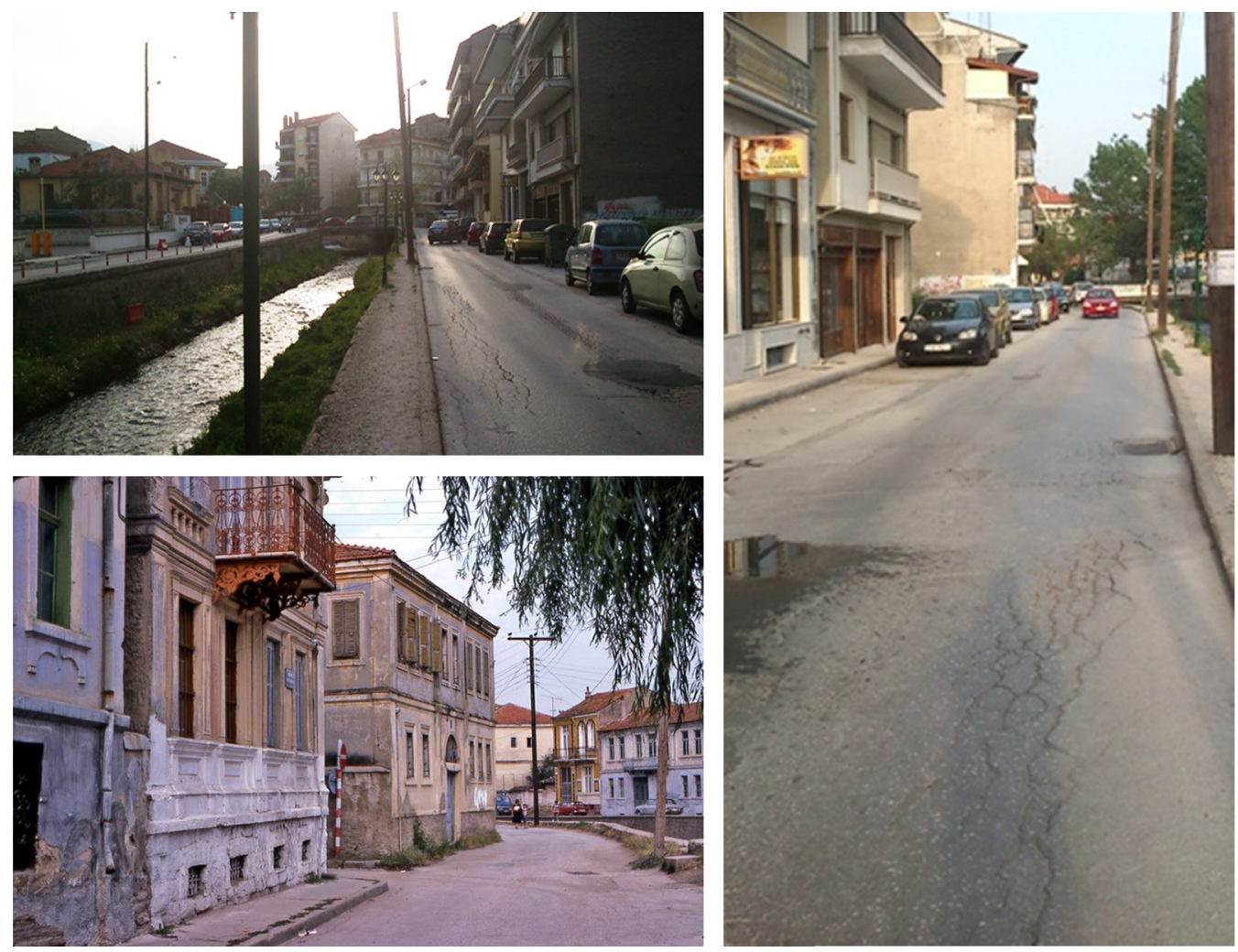

Fig. 1. River side routes in Florina.

Please cite this article in press as: Zoras, S., et al. Evaluation of the application of cool materials in urban spaces: A case study in the center of Florina. Sustainable Cities and Society (2014), http://dx.doi.org/10.1016/j.scs.2014.01.007 


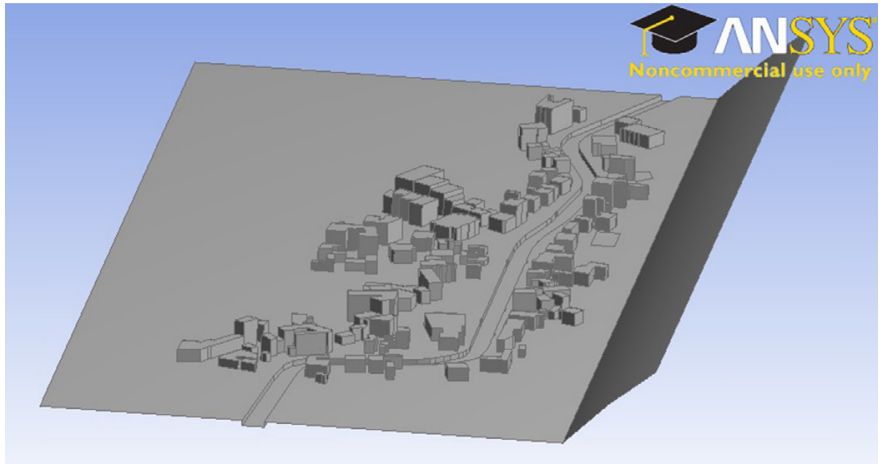

Fig. 2. Import of the three dimensional geometry.

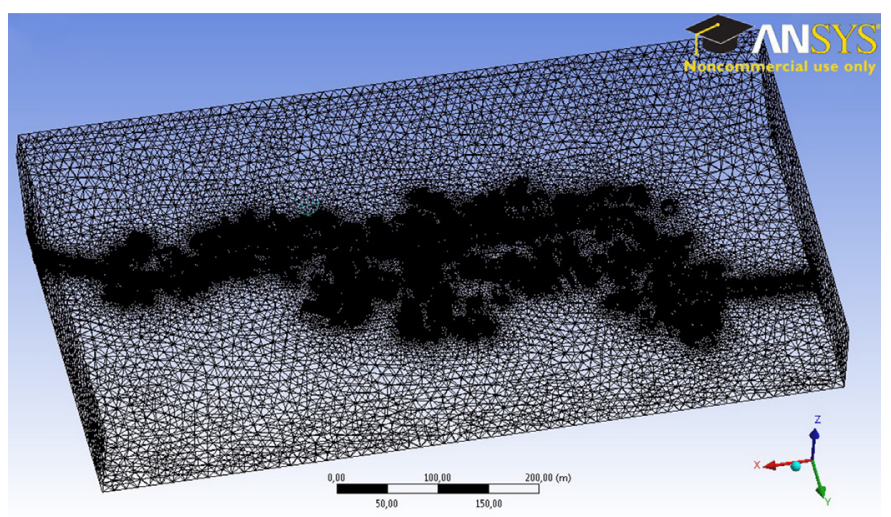

Fig. 3. Meshing elements of the area.

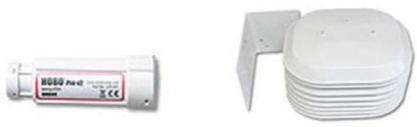

HOBO Pro V2 Temp/RH Data Logger
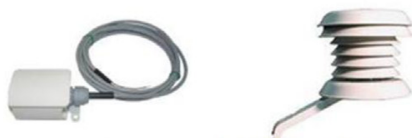

Outdoor Temperature sensor
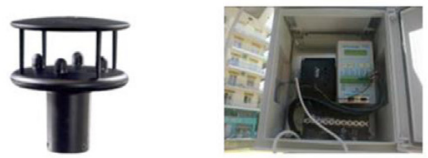

Wind Sonic Ultrasonic Wind Sensor

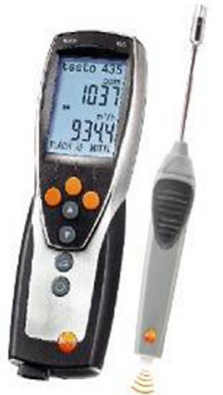

Fig. 4. Instrumentation of microclimatic measurements. rate. The structural surfaces should be reduced and replaced by water surfaces, soil and vegetation. Green roofs in the river side buildings or where people are accommodated would also contribute in the reduction of material thermal storage.

\section{Model verification}

Monitored data of the thermal conditions in the area of interest and surrounding locations resulted at the analytical verification of the CFD model and consequently the accurate simulation of both the current situation and proposed interventions. The ANSYS CFD model was used for the simulations.

The three dimensional geometry in a .dwg file was imported in the CFD software (Fig. 2). The more detailed the structural and 3D geometry of buildings, streets, pavements, urban equipment and vegetation is, the more representative and accurate simulation is. This .dwg file was imported and refined in the Design Modeler module of the simulation tool where solid surfaces (buildings, streets, pavements and trees) and the fluid domain area were defined. The fluid domain area encloses the study area by a dimension of $1000 \mathrm{~m} \times 1000 \mathrm{~m} \times 80 \mathrm{~m}$ (height) - this was at least 4 times the max height of structural domains in order to avoid flow reflection at boundaries and fluid returns during simulation.

The simulation domain was meshed (solid surfaces and fluid domain volume) and mesh was created at all area's surfaces (streets, pavements, facades on streets, facades not facing streets, roofs, etc.). The surfaces have been meshed by the Advanced Proximity and Curvature Function and the mesh dimensions have been selected by the criterion of the fully developed flow within the fluid domain. The typical element in the mesh had dimension of $1.0 \mathrm{~m}$, with denser mesh close to solid surfaces (facades, vegetation,

Table 2

Comparison between experimental and simulated data.

\begin{tabular}{llll}
\hline Material & \multicolumn{3}{l}{ Experimental/simulated } \\
\cline { 2 - 4 } & $T_{\text {air }}\left({ }^{\circ} \mathrm{C}\right) 1.8 \mathrm{~m}$ & WS $(\mathrm{m} / \mathrm{s}) 1.8 \mathrm{~m}$ & $T_{\text {surf }}\left({ }^{\circ} \mathrm{C}\right)$ \\
\hline Pavement flagstone & $27.16 / 27.85$ & $0.70 / 0.75$ & $27.80 / 28.3$ \\
Concrete brick & $27.40 / 27.97$ & $0.61 / 0.66$ & $34.50 / 34.80$ \\
Asphalt & $36.23 / 36.85$ & $0.68 / 0.63$ & $32.0 / 32.5$ \\
\hline
\end{tabular}

Table 3

Hourly mean meteorological data during August of 2010.

\begin{tabular}{|c|c|c|c|}
\hline Time Temperature $\left({ }^{\mathrm{O}} \mathrm{C}\right)$ & Wind speed $(\mathrm{m} / \mathrm{s})$ & Wind direction & $\begin{array}{l}\text { Solar radiation } \\
\left(\mathrm{W} / \mathrm{m}^{2}\right)\end{array}$ \\
\hline 01:0021.5 & 1.5 & 226 & 0 \\
\hline 02:0020.9 & 1.4 & 223 & 0 \\
\hline 03:0020.3 & 1.3 & 221 & 0 \\
\hline 04:0019.8 & 1.3 & 215 & 0 \\
\hline 05:0019.3 & 1.3 & 223 & 0 \\
\hline 06:0018.8 & 1.3 & 224 & 38 \\
\hline 07:0018.2 & 1.3 & 219 & 160 \\
\hline 08:0018.3 & 1.4 & 219 & 354 \\
\hline 09:0020.4 & 0.9 & 198 & 540 \\
\hline 10:0022.6 & 0.8 & 134 & 692 \\
\hline 11:0024.4 & 0.9 & 146 & 797 \\
\hline 12:0026.1 & 0.9 & 142 & 846 \\
\hline 13:0027.7 & 0.8 & 182 & 839 \\
\hline 14:0028.9 & 0.8 & 178 & 875 \\
\hline 15:0029.8 & 0.8 & 196 & 678 \\
\hline $16: 0030.3$ & 0.8 & 193 & 496 \\
\hline 17:0030.7 & 0.7 & 200 & 304 \\
\hline 18:0030.9 & 0.7 & 196 & 116 \\
\hline 19:0080.5 & 0.6 & 211 & 24 \\
\hline 20:0028.9 & 1.0 & 205 & 0 \\
\hline 21:0025.8 & 1.4 & 218 & 0 \\
\hline $22: 0023.9$ & 1.5 & 220 & 0 \\
\hline 23:0022.8 & 1.5 & 224 & 0 \\
\hline 24:0022.0 & 1.5 & 222 & 0 \\
\hline
\end{tabular}


Table 4

Thermal and optical properties of materials defined in the CFD model.

\begin{tabular}{|c|c|c|}
\hline & Reflection coefficient & Emission coefficient \\
\hline \multicolumn{3}{|l|}{ Conventional flooring and views materials } \\
\hline Street asphalt & $0.10^{\mathrm{a}}$ & $0.85-0.93(0.89)^{\mathrm{b}}$ \\
\hline Light-colored covering roofing/roofs (sheathing with pavement flagstones) & $0.35^{\mathrm{a}}$ & $0.90^{\mathrm{c}}$ \\
\hline Light-colored coatings & $0.60^{\mathrm{a}}$ & \\
\hline Medium-colored coatings (beige, gray) & $0.40^{\mathrm{a}}$ & \\
\hline Gray color coatings & & $0.87^{c}$ \\
\hline Dark colored coatings & $0.20^{\mathrm{a}}$ & \\
\hline Conventional structural material & & $0.80^{\mathrm{a}}$ \\
\hline \multicolumn{3}{|l|}{ Cool materials coverings/coatings ${ }^{\mathrm{d}}$ ( $\sim$ surface $\%$ of the total simulated area) } \\
\hline Asphalt - concrete based floor mortar $(\sim 18.5 \%)$ & 0.37 & 0.89 \\
\hline Sidewalk blocks and bricks $(\sim 36.1 \%)$ & 0.67 & 0.89 \\
\hline Pavement flagstones ( 1.5\%) & 0.68 & 0.92 \\
\hline Trees ( $0.9 \%)$ & 0.25 & 0.67 \\
\hline
\end{tabular}

a Greek Chartered Inst (2010).

b Incropera and De Witt (1990).

c Santamouris (2006).

d ABOLIN.

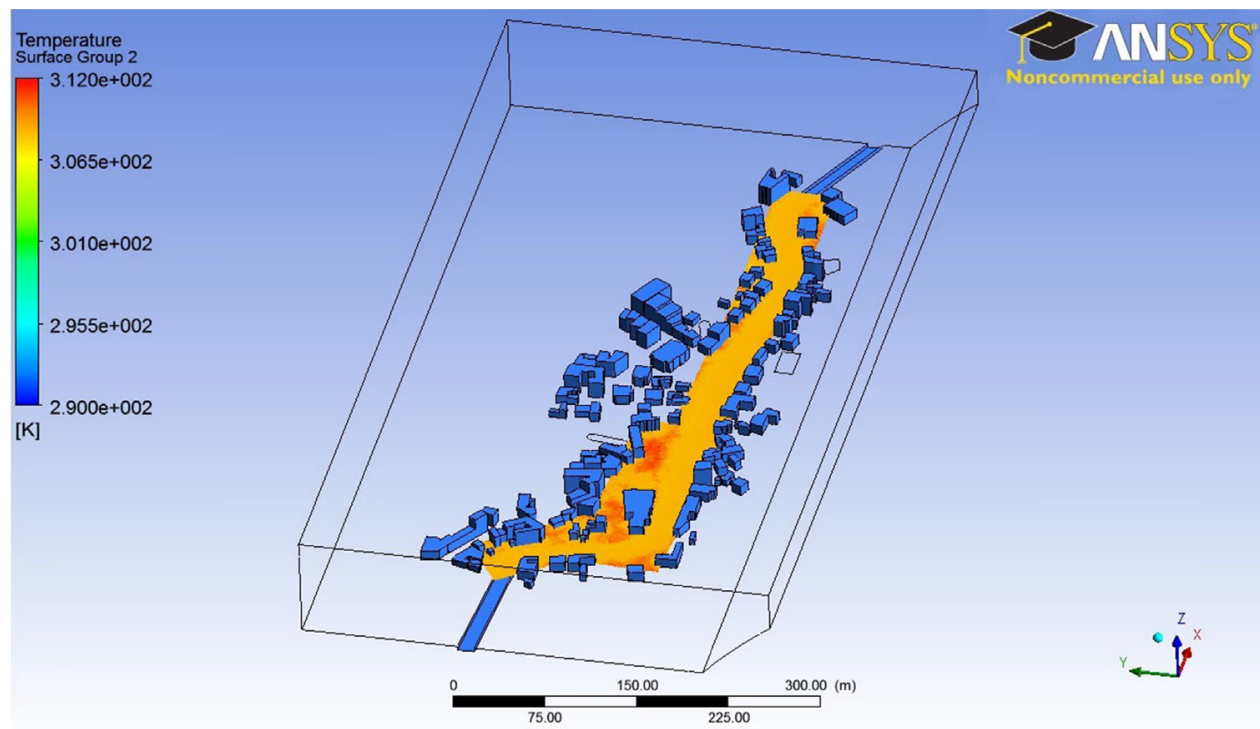

Fig. 5. Present mean air temperature at $1.8 \mathrm{~m}$ height calculated from at least 500 grid points at each street.

water elements, etc.) from 0.1 to $0.5 \mathrm{~m}$ (tetra-, hexa-, octa-surface elements). The final mesh constituted of 1,268,985 nodes and 6,723,255 elements (Fig. 3).

In order to prove the ANSYS CFD model validity for the open area simulation, the model was verified against experimental data that have been carried out during September 2011. The warmest day for the period of experiment was selected in terms of the completeness of the microclimatic data (i.e. air temperature, air velocity, surface temperature). Therefore, it was chosen September 13th, 2011, between 15:20 and 16:20 hours. The data used for validation of the model is the measurement data within the study area, i.e. the air temperature, the temperature of the material surfaces of streets, sidewalks and facades at $1.8 \mathrm{~m}$ in height and the wind speed at the same height.

The microclimatic parameters and specifically the air temperature $(\mathrm{T})$, the relative humidity $(\mathrm{RH})$, the wind speed (WS) and the wind direction (WD) were measured by a mini weather station (Fig. 4). The sensor for recording wind speed and direction was an ultrasonic wind sensor of 2-axis, with low start speed in $0.01 \mathrm{~m} / \mathrm{s}$. This sensor is suitable for measuring wind speed in densely urban centers, where the wind speed can be extremely low due to urban configuration and geometry. Surface temperatures were measured by the Testo 435 contact thermometer.

The simulation results were compared with the measured values of the surface temperature, ambient temperature and wind speed. Climate data from that period were obtained from the Florina meteorological station that belongs to the Public Power Energy Corporation and is located in the urban development, surrounded by conventional materials and being affected by human activities. These data were used to simulate the climatic condition in the intervention area and in places where measurement was made. Since surface temperature measurements were carried out during midday, the comparisons were made for the same period.

The concept of model validity was that meteorological input from Florina's station if applied in ANSYS CFD could efficiently calculate the thermal behavior of within the urban complex. From Table 2, a satisfactory convergence of the values between experiment and simulation can be noticed. Therefore, the achieved accuracy of the model that was developed for the study area was quite high. The above comparison substantiates the high reliability 


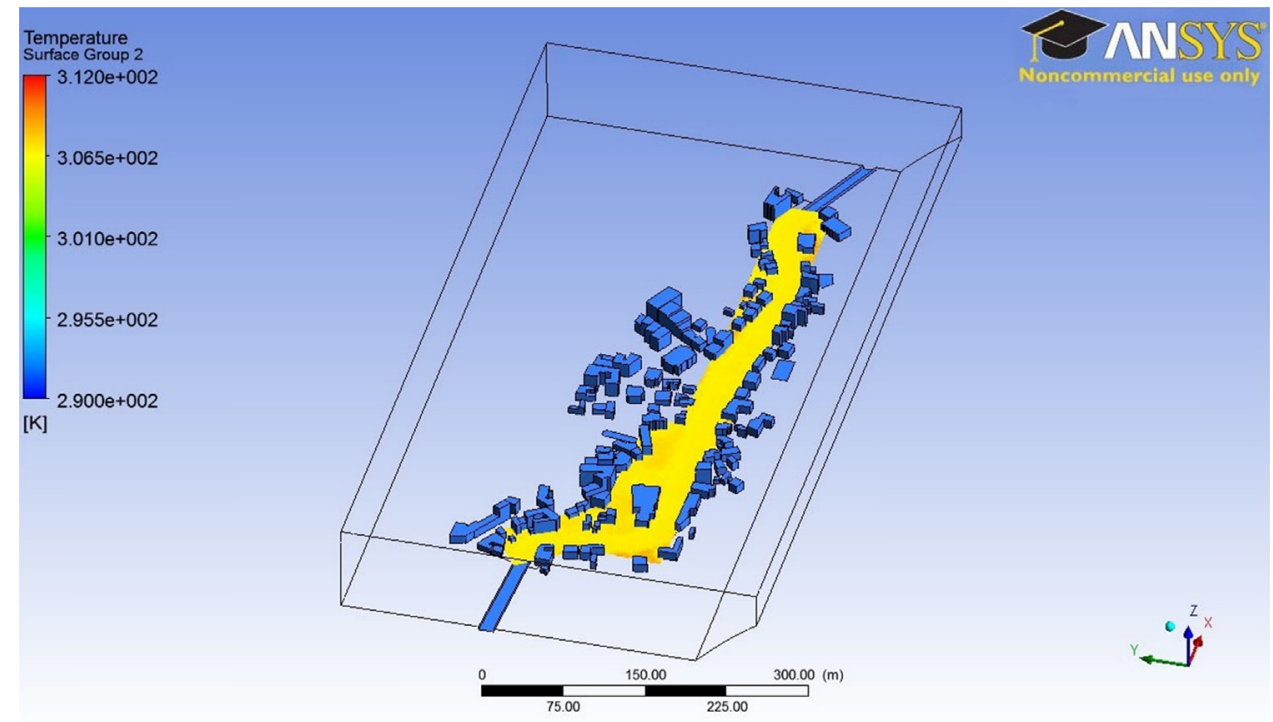

Fig. 6. Mean air temperature after rehabilitation at $1.8 \mathrm{~m}$ height calculated from at least 500 grid points at each street.

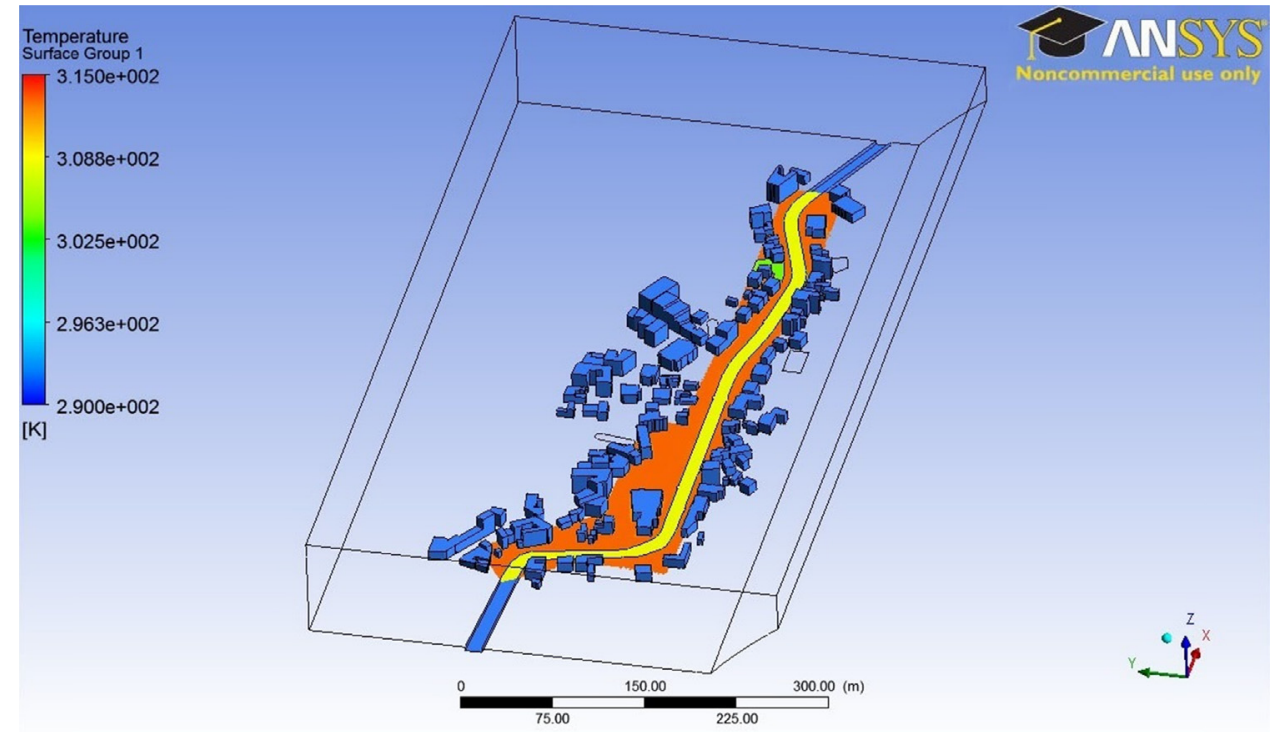

Fig. 7. Mean surface temperatures of the existing condition.

of the model for the assessment of both the current situation and bioclimatic upgrade in the study area.

\section{Mean maximum air temperature at noon of the warmest day}

Simulation of the average maximum summer period temperature has been carried out in the open area during noon of the warmest day. The warmest day was obtained from the period of the years 2009-2010, being the 21st of August 2010. Meteorological data from that day (Table 3 ) at noon were used in the simulation, in steady state mode, of the present and rehabilitated situation. At each case, the same meteorological data from Florina station were applied as input in ANSYS CFD with the respective materials and interventions of each configuration. This way modeling predicted the thermal situation in the urban complex with input general meteorological data of the city. In Table 4 the thermal and optical properties of materials defined in the CFD model are provided. In specific, the table presents the conventional materials for the present case and the selected cool materials for the rehabilitated case together with their percentage of coverage of the total simulated area.

It was assumed that in the open urban square and the linking routes in Florina, the average maximum temperatures appeared during the selected warmest day. Moreover, simulation has shown that the maximum temperatures within roads and the river side street appear at the same times. The area of interest was divided in the surface of the river side streets and river wind flow. The respective air temperatures were calculated at noon of the warmest day. Then, the resulted average maximum air temperature was compared for the case before and after rehabilitation. Figs. 5 and 6 depict air temperature field at each street along the river at $1.8 \mathrm{~m}$ height during noon of the warmest day before and after rehabilitation.

The simulated air temperature for each individual space (streets and open market) was obtained from at least 500 grid points of the mesh at $1.8 \mathrm{~m}$ height. ANSYS CFD was applied to simulate the predicted air temperatures before and after rehabilitation 


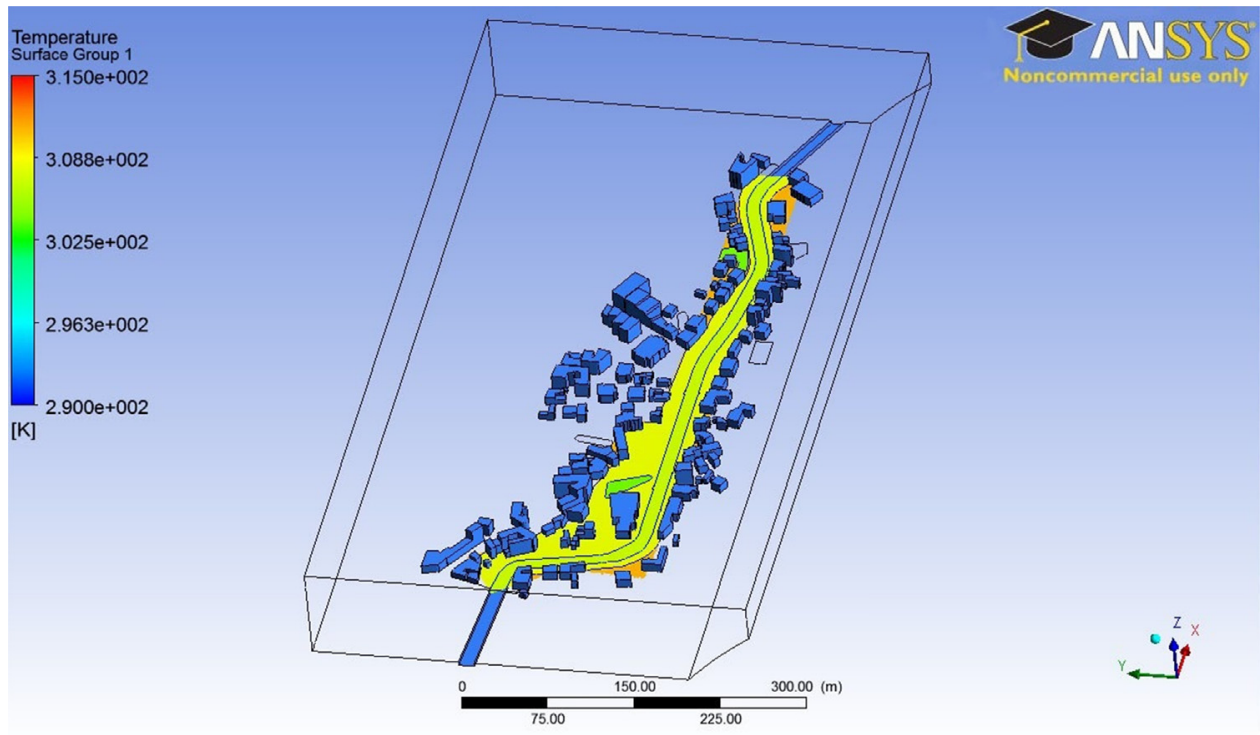

Fig. 8. Mean surface temperatures of the predicted bioclimatic case.

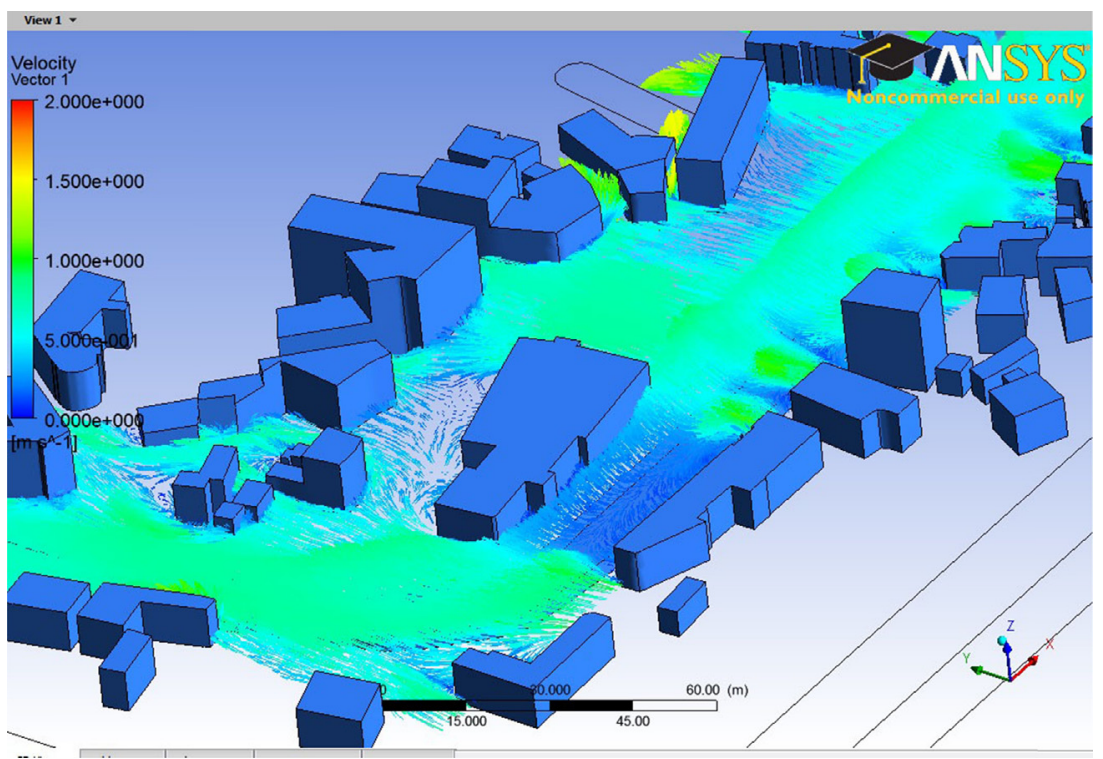

Fig. 9. Mean wind field velocity in the urban complex before bioclimatic rehabilitation.

with the surface areas in 21st of August 2010. The calculated total air temperature before and after case was $35.57^{\circ} \mathrm{C}$ and $34.18^{\circ} \mathrm{C}$, respectively. So, the air temperature improvement if bioclimatic measures are taken would be $1.39^{\circ} \mathrm{C}$.

\section{Mean surface temperature at noon of the warmest day}

CFD simulations have been carried out for the present case and for the proposed bioclimatic one. The results of the two simulations have compared concerning the warmest day of the 21st of August 2010. Figs. 7 and 8 display the surface temperatures for the present case and the improved one if bioclimatic techniques and practices are applied.

It was assumed that the mean surface temperature peaks during the warmest day and thus, it was calculated for all the individual roads and the market place separately. Therefore, it was assumed that the calculated surface temperatures are maximum for each individual road or open space. The mean surface temperature during noon of the 21st of August for all surfaces reached $38.21^{\circ} \mathrm{C}$ in contrast with the proposed bioclimatic configuration that reached $34.69^{\circ} \mathrm{C}$. The total predicted temperature difference was $3.52^{\circ} \mathrm{C}$. The significant material surface temperature reduction was due to shadowing from vegetation, water surfaces, green roofs, cool asphalt and cool flagstones of pavements and sidewalks.

\section{Wind field during the typical summer day}

Transient simulation of the wind field during the typical summer day with meteorological input of the area has been carried out. The typical wind field between 10:00 and 18:00 hours has been simulated in the area under consideration. From Figs. 9 and 10 it was concluded that at $1.80 \mathrm{~m}$ height the wind velocity and turbulence would not change significantly due to the proposed bioclimatic interventions. Velocity vectors in the streets and in the open square place do not differ significantly at two cases with velocities below 


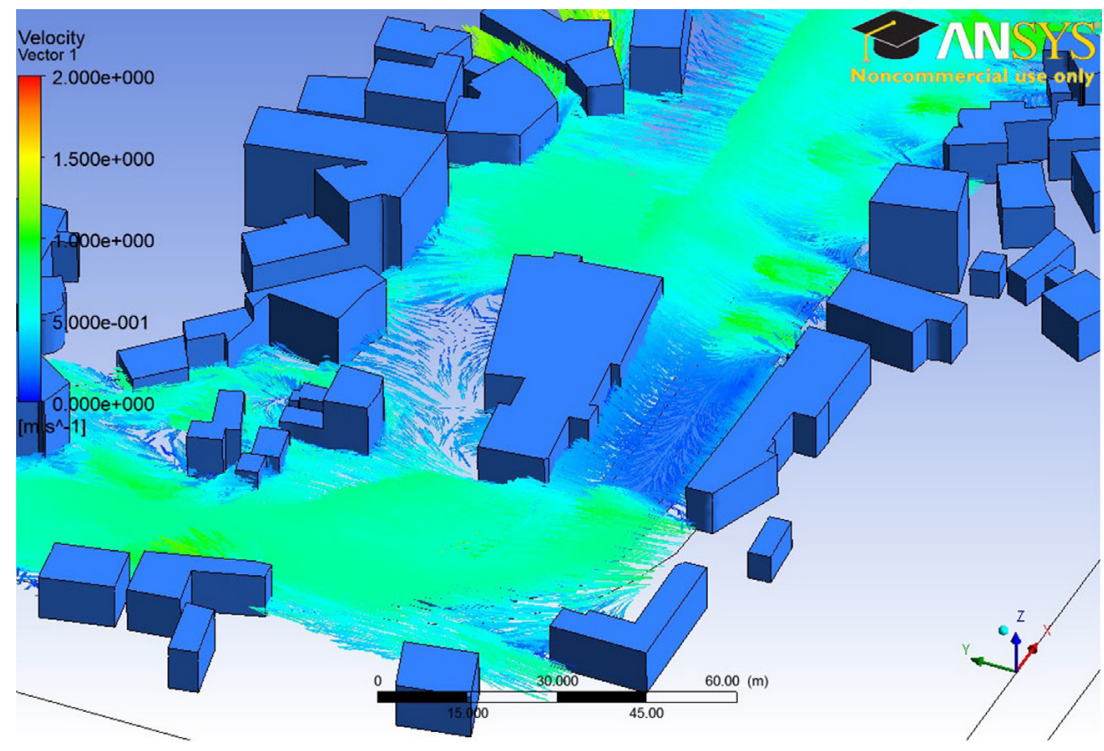

Fig. 10. Mean wind field velocity in the urban complex after bioclimatic rehabilitation.

$1.0 \mathrm{~m} / \mathrm{s}$ at all spaces (mean wind velocity before $0.578 \mathrm{~ms}^{-1}$, mean wind velocity after $0.574 \mathrm{~ms}^{-1}$ ). Generally, human comfort would not be affected at all open locations in relation to wind flow changes due to insignificant differences in velocities before and after rehabilitation.

\section{Conclusions}

Computational fluid dynamics simulation predicted the thermal conditions at the present case and the bioclimatically reformatted one. Each targeted parameter would improve if the proposed rehabilitation would take place in future. Relatively low air temperature improvement may lead to significant thermal comfort improvement. This is because thermal comfort is rather independent from air temperature but mostly correlated to radiant temperature. Note that, the wind field of velocities was approximately the same for the case before and after rehabilitation and therefore, it would not influence significantly the human thermal comfort conditions.

Reflection coefficients of cooled materials were higher than the conventional materials but emission coefficients were approximately the same. Therefore, the significance of roofs, green areas and trees within the open urban complex in relation to the improvement of air temperature is rather obvious. Relatively high thermal comfort improvement is "easier" to be succeeded if surface thermal exchange is manipulated by any of the abovementioned ways. The exact influence of a bioclimatic intervention to microclimatic parameters must be studied in relation to urban complexity and climatic zone characteristics. Nevertheless, during the cold period, "cool" materials' thermal contribution would enforce air temperatures to lower levels. Simulation procedure should be carried for the course of a year in order to assess the total balance of cooling effects in the area of interest.

\section{References}

ABOLIN. (2011). Technical material brochures \& certificates.

ANSYS-CFD-SOFTWARE. http://www.ansys.com/Products/Simulation+Technology/ Fluid+Dynamics

Dimoudi, A., Kantzioura, A., Zoras, S., Pallas, C., \& Kosmopoulos, P. (2013). Investigation of urban microclimate parameters in an urban centre. Energy and Buildings, $64,1-9$

Fintikakis, N., Gaitani, N., Santamouris, M., Assimakopoulos, M., Assimakopoulos, D. N., Fintikaki, M., et al. (2011). Bioclimatic design of open public spaces in the historic centre of Tirana, Albania. Sustainable Cities and Society, 1, 54-62.

Gartland, L. (2008). Heat islands: Understanding and mitigating heat in urban areas. Sterling, Virginia: Earthscan.

Gilbert, O. L. (1991). The ecology of urban habitats. London: Chapman \& Hall.

Greek Technical Chartered Institution 20701-1.(2010). Analytical National Standards of Parameters of Estimating Building Energy Performance Energy Class Certificate Production.

Incropera, F. P., \& De Witt, D. P. (1990). Fundamentals of heat and mass transfer. London: Wiley.

Livada, I., Santamouris, M., Niachou, K., Papanikolaou, N., \& Mihalakakou, G. (2002). Determination of places in the great Athens area where the heat island effect is observed. Theoretical \& Applied Climatology, 71, 219-230.

Matzarakis, A., Rutz, F., \& Mayer, H. (2006). Modelling the thermal bioclimate in urban areas with the RayMan model. In Proceedings of the PLEA 2006 conference, Vol. II (pp. 449-453).

Oke, T. P. (1973). City size and the urban heat island. Atmospheric Environment, 14, 769-779.

PHOENICS software tool: http://www.cham.co.uk/

Santamouris, M. (Ed.). (2006). Environmental design of urban buildings. London: Earthscan.

Stavrakakis, G. M., Tzanaki, E., Genetzaki, V. I., Anagnostakis, G., Galetakis, G., \& Grigorakis, E. (2011). A computational methodology for effective bioclimatic-design applications in the urban environment. Sustainable Cities and Society, 1, 54-62. www.cres.gr/kape/Scientific_Guide_19_7.pdf Accessed 09.09.13. 